\title{
Volatility Spillovers in Capesize Forward Freight Agreement Markets
}

\author{
Xiaoxing Gong ${ }^{1,2}$ and Jing $\mathrm{Lu}^{1}$ \\ ${ }^{1}$ Transportation Management College, Dalian Maritime University, Dalian 116026, China \\ ${ }^{2}$ Collaborative Innovation Center for Transport Studies, Dalian Maritime University, Dalian 116026, China \\ Correspondence should be addressed to Xiaoxing Gong; gong_xiaoxing@dlmu.edu.cn
}

Received 3 July 2016; Accepted 9 October 2016

Academic Editor: Xiaofeng Xu

Copyright (c) 2016 X. Gong and J. Lu. This is an open access article distributed under the Creative Commons Attribution License, which permits unrestricted use, distribution, and reproduction in any medium, provided the original work is properly cited.

\begin{abstract}
This paper is to investigate spillovers in the Capesize forward freight agreements (FFAs) markets before and after the global financial crisis. The paper chooses four Capesize voyage routes FFAs (C3, C4, C5, and C7), two time-charter routes FFAs (BCIT/C average, BPI T/C average), and spot rates as research subjects, covering the periods 3 January 2006 to 24 December 2015. This paper applies Volatility Spillover Multivariate Stochastic Volatility (VS-MSV) model to analyze volatility spillover effects and estimates the parameters via software of Bayesian inference using Gibbs Sampling (BUGS), the deviance information criterion (DIC) used for goodness-of-fit model. The results suggest that there are volatility spillover effects in certain Capesize FFAs routes, and the effects from spot rates to FFAs take place before crisis, yet they are bilateral after crisis. With the development of shipping markets, the correlations between FFAs and spot rate are enhanced, and it seems that the effects depend on market information and traders' behavior. So practitioners could make decisions according to the spillovers.
\end{abstract}

\section{Introduction}

Cross-market information transmission is a research area that received a lot of attention from both academia and practitioners [1]. With the development of shipping derivative markets, the relationships between related markets are closer. After global financial crisis, the financial risks transmission enhances relationships among different shipping derivative markets. Unlike the variable's first moment relationship reflected in the price spillover effect, the volatility spillover effect reflects the variable's second moment relationship, in which market volatility is influenced not only by its own early stage but also by volatility coming from other markets [2]. The volatility spillover effect exists widely in different shipping derivative markets. It is an important aspect of volatility in shipping industry.

As a main component of shipping derivatives, forward freight agreements (FFAs) are over-the-counter products made on a principal-to-principal basis at the beginning, and now they are traded both over the counter and through exchange. Freight derivatives provide a means of hedging exposure to freight market risk through the trading of specified time-charter and voyage rates for forward positions.

According to the efficient market hypothesis, the FFAs price should be unbiased estimator of the spot price, which is the underlying asset. Yet it is not always true in FFAs markets. So the relationship between FFAs and spot rates is paid attention [3-8], especially the spillover effects. Chung and Weon [9] employ two versions of bivariate asymmetric mixed normal GARCH models to capture the skewness and kurtosis detected in both the conditional and unconditional return distributions of dry-bulk freight rates. Li et al. [10] investigate spillover effects and dynamic correlations between shipping spot and derivatives markets under the multivariate generalized autoregressive conditional heteroscedasticity framework and find that spillovers in returns are unilateral from onemonth FFA to spot markets, while they are bilateral between one-month and two-month FFA markets. Sogiakas and Karathanassis [11] examine volatility spillovers between spot and derivatives markets without accounting for possible disequilibria in the long term relationship that could potentially result in spurious spillover effects and provide evidence of 
a time-varying spillover effect from derivatives to spot markets. Alexandridis et al. [12] investigate the economic spillovers between time-charter rates, freight futures, and freight options prices in the dry-bulk shipping industry; the results indicate the existence of significant information transmission in both returns and volatilities between the three related markets. Shi et al. [13] use a univariate generalized ARCH model to capture the volatility characteristics of freight derivative returns and apply time-varying copula models to describe the nonlinear dependence between returns of spot and freight derivatives. As we have known, since global financial crisis, in order to avoid credit risk, over $90 \%$ of FFAs trading volume is through clearing house after global economic crisis [14]. That is to say the crisis changed the manner of settlement for FFAs; however, whether it influences relationship between FFAs and spot rate should be studied furthermore.

With the development of research, the relationships are paid attention between FFAs and commodity markets. Chou [15] applies the vector autoregressive moving-average model (VARMA) and uses variables from one-year FFAs and the global oil index to analyze the relationships between the two instruments. Chou et al. [16] attempt to discover the dynamic relationship between crude oil prices and the global steel price index and find that the crude oil price moves prior to movements in the global steel price index. Kavussanos et al. (2014) investigate economic spillovers between the freight and commodity derivatives markets, and the investigation of various types of commodities transported under different types of freight contracts reveals that in most cases new information appears first in the returns and volatilities of the commodities futures markets, before it is spilled over into the freight derivatives markets. As is well known, bulk shipping is the tramp shipping, and one ship could run on different routes. So there may be relationships among FFAs prices on different voyage routes. At the same time, different types of ships could run on the same route; therefore, FFAs price of different types of ships could be related, such as Capesize and Panamax. In this paper, the spillover effects are investigated among voyage routes FFAs prices and between time-charter routes FFAs, comparing before and after global financial crisis, in order to analyze volatility characters of FFAs markets.

Now the main model studying volatility in shipping markets is generalized autoregressive conditional heteroscedasticity $(\mathrm{GARCH})$ model $[4,17,18]$. With the research going, extended models are applied. Alizadeh and Nomikos [19] investigate the relationship between the dynamics of the term structure and time-varying volatility of shipping freight rates, using augmented EGARCH models, and find support for the argument that the volatility of freight rates is related to the shape of the term structure of the freight market. Alizadeh (2013) investigates the price volatility and trading volume relationship in the forward freight agreement (FFA) market for dry-bulk ships over the period 2007-2011, using an exponential GARCH model, and finds that FFA price changes have a positive impact on trading volume. Alizadeh et al. [20] examine the effectiveness of alternative hedging methods, including a bivariate Markov regime switching GARCH model, in hedging tanker freight rates, and find evidence supporting the argument that the tanker freight market is characterized by different regimes. Tsouknidis [21] examines the existence of dynamic volatility spillovers within and between the dry-bulk and tanker freight markets by employing the multivariate DCC-GARCH model, and results reveal the existence of large time-varying volatility spillovers across shipping freight markets, which are more intense during and after the global financial crisis. As another volatility models, the Stochastic Volatility models are used widely for researching volatility of financial markets [22-25]. Some literatures show that the SV models are better than GARCH models for analyzing volatility in financial markets $[26,27]$. Yet there are few literatures using the SV models to investigate volatility in shipping. The paper applies the extended SV model to investigate spillover effects in FFAs markets.

In addition, some researches focus on investigating Panamax FFAs market, while Capesize FFAs market is more important for China. The reason is that China is the biggest iron importer, and the volume of imports is over $70 \%$ of the world, which is mainly transported by Capesize ships. So this paper investigates the volatility spillover effects among Capesize FFAs markets, Panamax FFAs markets, and spot markets, comparing with different Capesize routes and different periods, before and after global economic crisis, in order to get some findings to help shipping operation and management. This will also be helpful in trade using FFAs which could manage shipping risk and improve management level. The remainder of this paper is structured as follows. Section 2 presents the theoretical framework and Volatility Spillover Multivariate Stochastic Volatility (VS-MSV) model. Section 3 is the numerical statistics analysis. Section 4 contains empirical results. Section 5 concludes the paper.

\section{Methodology}

2.1. VS-MSV Model. Harvery et al. [28] and So et al. [29] put forward Multivariate Stochastic Volatility (MSV) model on the basis of Stochastic Volatility (SV) model.

The basic SV model is as follows:

$$
\begin{aligned}
& y_{t}=\varepsilon_{t} \exp \left(\frac{h_{t}}{2}\right), \quad t=1,2, \ldots, T, \varepsilon_{t} \sim \text { i.i.N }(0,1), \\
& h_{t}=\alpha+\beta\left(h_{t-1}-\alpha\right)+\eta_{t}, \quad \eta_{t} \sim \text { i.i. } N(0,1) .
\end{aligned}
$$

$y_{t}$ indicates FFAs return of one route at time $t$ and $h_{t}$ is a stationary $\mathrm{AR}(1)$ process. $\varepsilon_{t}$ is a martingale difference, which follows the normal distribution, $\varepsilon_{t}$ and $\eta_{t}$ are contemporaneously dependent, and $\alpha$ and $\beta$ are parameters to be estimated. $T$ is the sample size.

Similar to basic model, MSV model is as follows:

$$
\begin{aligned}
& y_{i t}=\xi_{i t} \exp \left(\frac{h_{i t}}{2}\right), \quad i=1,2, \ldots, m, t=1,2, \ldots, T, \\
& h_{i t}=\alpha_{i}+\varphi_{i}\left(h_{i, t-1}-\alpha_{i}\right)+\eta_{i t}, \quad i=1,2, \ldots, m .
\end{aligned}
$$

$y_{i t}$ indicates FFAs returns of different routes at time $t$. Random error vectors $\xi_{i t}$ and $\eta_{i t}$ are multivariate normal vectors, 
and the mean values are both zero. $\alpha_{i}$ and $\varphi_{i}$ are parameters to be estimated.

MSV model indicates the impact of $h_{i, t-1}$ on $h_{i t}$ without considering the impact of other $h_{i t}(j \neq t, j \neq t-1)$, so it could not analyze the volatility spillover effects with SV or MSV. With the development of economic globalization, the volatility spillover effect becomes common. In order to study the effect, parameter vector $\varphi_{i}$ is extended to matrix $\Phi[30]$.

$$
\Phi=\left(\begin{array}{ccc}
\varphi_{11} & \cdots & \varphi_{1 m} \\
\cdots & \cdots & \cdots \\
\varphi_{m 1} & \cdots & \varphi_{m m}
\end{array}\right)
$$

where $\varphi_{i j}$ indicates the impact of $h_{j, t-1}$ on $h_{i, t}(i \neq j)$. So the Volatility Spillover Multivariate Stochastic Volatility (VSMSV) model is as follows:

$$
\begin{aligned}
y_{i t} & =\Omega \xi_{i t}, \quad \xi_{i t} \sim N\left(0, \Sigma_{\xi}\right), \\
\Omega & =\operatorname{diag}\left(\exp \left(\frac{h_{1 t}}{2}\right), \exp \left(\frac{h_{2 t}}{2}\right), \ldots, \exp \left(\frac{h_{m t}}{2}\right)\right), \\
h_{i t} & =\alpha_{i}+\Phi\left(h_{i, t-1}-\alpha_{i}\right)+\eta_{i t}, \quad \eta_{i t} \sim N\left(0, \Sigma_{\eta}\right) .
\end{aligned}
$$

Here, $y_{i t}$ is returns of FFAs for kinds $i$ at time $t . \xi_{i t}$ and $\eta_{i t}$ are the random variables and independent, identically distributed with normal distribution, and the mean values are both zero, yet the variances are $\Sigma_{\xi}$ and $\Sigma_{\eta}$, respectively. $h_{i t}$ are the volatilities, $\alpha_{i}$ and $\Phi$ are parameters, and $\Phi$ are persistence parameters.

The covariance matrix $\Sigma_{\xi}$ is given by

$$
\begin{aligned}
\sum_{\xi} & =E\left(\xi_{t} \xi_{t}^{T}\right)=E\left(\begin{array}{ccc}
\xi_{1 t}^{2} & \cdots & \xi_{1 t} \xi_{m t} \\
\cdots & \cdots & \cdots \\
\xi_{m t} \xi_{1 t} & \cdots & \xi_{m t}^{2}
\end{array}\right) \\
& =\left(\begin{array}{ccc}
1 & \cdots & \rho_{1 m} \\
\cdots & \cdots & \cdots \\
\rho_{1 m} & \cdots & 1
\end{array}\right) .
\end{aligned}
$$

Random error vector $h_{i t}$ is the multivariate normal vector, $\eta_{i t} \sim N\left(0, \Sigma_{\eta}\right) . \Sigma_{\eta}$ is given by

$$
\Sigma_{\eta}=\left(\begin{array}{ccc}
E\left(\eta_{1 t}^{2}\right) & \cdots & E\left(\eta_{1 t} \eta_{m t}\right) \\
\cdots & \cdots & \cdots \\
E\left(\eta_{m t} \eta_{1 t}\right) & \cdots & E\left(\eta_{m t}^{2}\right)
\end{array}\right) .
$$

2.2. Parameter Estimation and Test. The Bayesian analysis and Markov Chain Monte Carlo (MCMC) method are used to estimate parameters. Finally, it gets the Bayesian estimation results. In VS-MSV model, unknown parameters include $\alpha_{i}$ and $\Phi$ (including $2 m+m^{2}$ unknown parameters).

Firstly, suppose that the parameters of vector $\theta$ are independent, and $p(\cdot)$ indicates probability density function of random stochastic variable. Joint prior density of unknown parameters and unobservable variables is as follows:

$$
\begin{aligned}
& p(\theta)=p\left(\alpha, h_{1}^{T}, h_{2}^{T}, \ldots, h_{r}^{T}\right)=p(\alpha)\left[\prod p\left(h_{t}^{T}\right)\right] \\
& \quad=\left[\prod p\left(\alpha_{i}\right) p\left(\sigma_{\eta i}^{2}\right)\right]\left[\prod p\left(\varphi_{i j}\right)\right]\left[\prod \prod p\left(h_{i t}\right)\right] .
\end{aligned}
$$

Secondly, according to Bayesian, the posterior density of $\theta$ is fixed.

$$
\begin{aligned}
p(\theta \mid y) & \propto p(\theta) p(y \mid \theta) \\
& \propto p(\alpha)\left[\prod p\left(h_{t}^{T}\right)\right]\left[\prod p\left(y_{t} \mid \theta\right)\right] .
\end{aligned}
$$

Thirdly, Bayesian parameters estimation is obtained with Monte Carlo method.

$$
\begin{aligned}
& \widehat{\varphi}_{i t}=\frac{1}{L-s} \sum \varphi_{i i}, \quad i=1,2, \ldots, m ; t=1,2, \ldots, T, \\
& \widehat{\varphi}_{i t}=\frac{1}{L-s} \sum \varphi_{i j}, \\
& \qquad i \neq j ; i, j=1,2, \ldots, m, t=1,2, \ldots, T, \\
& \widehat{\alpha}=\frac{1}{L-s} \sum \alpha_{i}^{l}, \quad i=1,2, \ldots, m ; t=1,2, \ldots, T, \\
& \widehat{\sigma}_{\eta i}^{2}=\frac{1}{L-s} \sum\left(\sigma_{\eta i}^{2}\right)^{l}, \quad i=1,2, \ldots, m, l \in(s, L) .
\end{aligned}
$$

The goodness-of-fit of model is a deviance information criterion (DIC) [31] that is based on the posterior distribution of the deviance statistic.

$$
D(\theta)=-2 \ln p(y \mid \theta)+2 \ln f(y) .
$$

Here $p(y \mid \theta)$ is the likelihood function for the observed data vector $y$ given the parameter vector $\theta$, and $f(y)$ is some standardizing function of the data alone. The DIC is defined as

$$
\begin{aligned}
\mathrm{DIC} & =\bar{D}+P_{D}=2 \bar{D}-D(\bar{\theta}), \\
\bar{D} & =E \theta \mid y[D] .
\end{aligned}
$$

The fit of a model is summarized by the posterior expectation of the deviance, while the complexity of a model is captured by the effective number of parameters $P_{D}$. Smaller values of DIC indicate a better-fitting model.

2.3. Judgment of Volatility Spillover. Firstly, $y_{i t}$ is the return of the market $i$. In order to judge the volatility spillover of different markets, significance test is done for parameter $\varphi_{i j}$ $(i \neq j)$. Null hypothesis is as follows: $H_{0}: \varphi_{i j}=0(i \neq j)$.

Standard deviation of parameter $\widehat{\varphi}_{i j}$ is $S_{\widehat{\varphi}_{i j}}$.

$$
S_{\widehat{\varphi}_{i j}}=\sqrt{\operatorname{var}\left(\varphi_{i j}\right)}=\sqrt{\operatorname{var}\left(\frac{1}{L-s} \sum \varphi_{i j}\right)} .
$$

Here $\varphi_{i j}(i \neq j)$ follows normal distribution. Due to definition of $\chi^{2}$ distribution, $S_{\widehat{\varphi}_{i j}}$ follows the $L$ degrees of freedom of a $\chi^{2}$ distribution. So, the statistic is structured.

$$
t=\frac{\widehat{\varphi}_{i j}}{S_{\widehat{\varphi}_{i j}}} .
$$


If $|t|<t(L)$, the null hypothesis is accepted, which shows that $\varphi_{i j}=0$ is significant, or the null hypothesis is rejected. Secondly, if parameter $\varphi_{i j}=0(i \neq j)$ is significant, the volatility spillover effect of the market $j$ to the market $i$ is existing, or there is no effect.

2.4. Settings of Prior Density. It is important to decide joint prior density $p(\theta)$ of unknown parameters and nonobservable variables, before estimating parameters in SV model with MCMC method, and here the key point is to set the initial value.

Due to persistence of volatility, Kim et al. [32] found the matrix, composed of $h_{i t}$ and $y_{i t}$, which is a singular matrix, and values of $\varphi_{i t}$ and $\sigma_{\eta i}^{2}$ are close to zero. If prior value of $\varphi_{i t}$ is close to $1, \alpha$ goes away, and it becomes the nonidentifier. According to the research of Meng et al. [33], the setting of prior density values is as follows:

$$
\begin{aligned}
\sigma_{\eta i}^{2} & \sim \operatorname{IG}(2.5,0.025), \quad i=1,2, \ldots, m, \\
\varphi_{i t}^{*} & \sim \operatorname{beta}(20,1.5), \\
\varphi_{i t}^{*} & =\frac{\left(\varphi_{i t}+1\right)}{2}, \\
\alpha_{i} & \sim N(0,0.01), \\
\varphi_{i t} & \sim N(0,0.1), 2, \ldots, m, \\
h_{i 0} & \sim N\left(\alpha_{i}, \sigma_{\eta i}^{2}\right), \\
h_{i t} & \sim N\left[\alpha_{i}+\sum \varphi_{i j}\left(h_{i, t-1}-\alpha_{i}\right), \sigma_{\eta i}^{2}\right],
\end{aligned}
$$

$$
i=1,2, \ldots, m \text {. }
$$

\section{Data and Preliminary Analysis}

3.1. Data Selection. FFAs contracts are standardized contract to be settled in future, and some of its information is fixed, including routes, quantity of goods, and ship type. Baltic Exchange FFAs routes cover four standard ships, including BFA Capesize (C3, C4, C5, C7, and BCI T/C average), BFA Panamax (P1a, P2a, P3a, and BPI T/C average), BFA Supramax (BSI T/C average), and BFA Handysize (BHSI T/C average). Details are in Table 1.

From history data of trading, percent of Panamax FFAs trading is 54\% in 2008, and Capesize is 35\%. But in 2009, the Panamax is $42 \%$, and Capesize is $46 \%$. In 2012, they are about $50 \%$ and $39 \%$. There may be two reasons. The first is people finding that it is more important for the operators of Capesize to manage risks with FFAs from the global crisis; the second is the larger trading tonnage of Capesize and statistic data by "lot" for Baltic Exchange (one lot equals $1000 \mathrm{mt}$ ); therefore, the percent is higher. In addition, China is the biggest iron importer, and the volume of imports is over $70 \%$ of the world, which is transported by Capesize ships. So the paper
TABLE 1: The information of dry FFAs.

\begin{tabular}{lccc}
\hline Route & Segment & Route definition & $\begin{array}{c}\text { Size } \\
\text { (104 DWT) }\end{array}$ \\
\hline C3 & Capesize & Tubarao/Beilun + Baoshan & 15 \\
C4 & Capesize & Richards Bay/Rotterdam & 15 \\
C5 & Capesize & W Australia/Beilun/Baoshan & 15 \\
C7 & Capesize & Bolivar/Rotterdam & 15 \\
BCIT/C & Capesize & Time-charter average & 17.2 \\
average & Panamax & Transatlantic & 7.4 \\
P1a & Panamax & Cont. trip far east & 7.4 \\
P2a & Panamax & Transpacific round voyage & 7.4 \\
P3a & Time-charter average & 7.4 \\
BPI T/C & Panamax & & \\
$\begin{array}{l}\text { average } \\
\text { BSI T/C }\end{array}$ & Supramax & Time-charter average & 5.2 \\
$\begin{array}{l}\text { average } \\
\text { BHSI T/C } \\
\text { average }\end{array}$ & Handy & Time-charter average & 2.8 \\
\hline
\end{tabular}

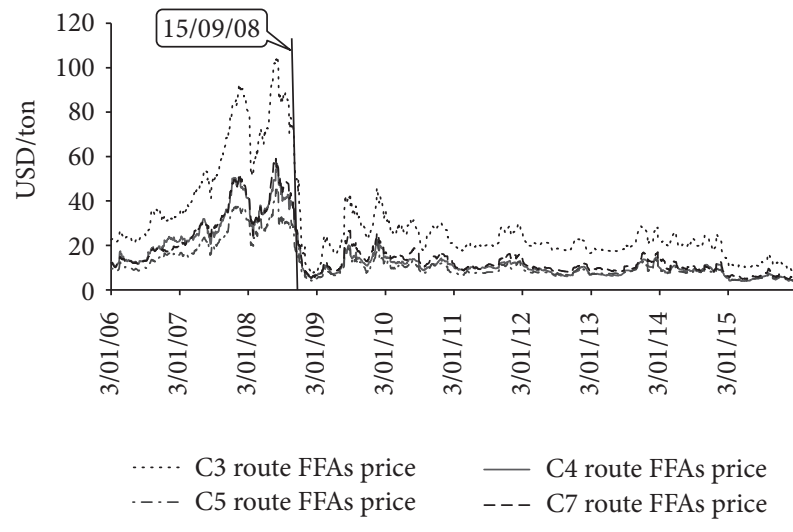

Figure 1: FFAs price of C3, C4, C5, and C7.

focuses on Capesize FFAs, investigating its volatility spillover. The data set comprises daily observations of Capesize FFAs price, voyage routes $\mathrm{C} 3, \mathrm{C} 4, \mathrm{C} 5$, and $\mathrm{C} 7$, time-charter routes $\mathrm{BCIT} / \mathrm{C}$ average and BPI T/C average, and spot rate of Capesize. It covers the periods 3 January 2006 to 24 December 2015. The data from the Baltic Exchange are shown in graphical form in Figures 1 and 2. All prices are transformed to natural logarithm difference, according to literatures $[1,34]$. In order to investigate the volatility characters of FFAs markets before and after the global financial crisis, the paper chooses a demarcation point of financial crisis, the 15 of September 2008, the day Lehman Brothers went bust, which marks the global financial crisis [35]. There are 664 samples before the financial crisis, and the others are 1819 samples.

3.2. Statistic Characters and Test. The analysis of statistic characters is the basis of studying FFAs price volatilities, and the results are shown in Table 2. According to the results, there are three findings. The first one is high volatility in FFAs markets after financial crisis. The standard deviation is a measure that summarizes the amount by which every value within 
TABLE 2: The statistic characters of returns.

\begin{tabular}{|c|c|c|c|c|c|c|c|}
\hline & $\mathrm{C} 3$ & $\mathrm{C} 4$ & C5 & $\mathrm{C} 7$ & BCIT/C average & BPIT/C average & $\mathrm{BCI} \mathrm{T} / \mathrm{C}$ \\
\hline \multicolumn{8}{|c|}{ Before 2008 financial crisis } \\
\hline Mean & 0.001 & 0.001 & 0.001 & 0.001 & 0.001 & 0.001 & 0.001 \\
\hline Median & 0.002 & 0 & 0.001 & 0.001 & 0.001 & 0 & 0.003 \\
\hline $\operatorname{Max}$ & 0.078 & 0.188 & 0.179 & 0.199 & 0.247 & 0.201 & 0.146 \\
\hline Min & -0.106 & -0.205 & -0.244 & -0.212 & -0.169 & -0.122 & -0.168 \\
\hline $\mathrm{SD}$ & 0.018 & 0.026 & 0.027 & 0.022 & 0.027 & 0.02 & 0.029 \\
\hline Skewness & -1.229 & -0.207 & -1.075 & -0.226 & 1.164 & 1.596 & -0.558 \\
\hline kurtosis & 10.504 & 15.143 & 18.439 & 27.996 & 23.204 & 26.792 & 7.939 \\
\hline $\mathrm{J}-\mathrm{B}$ & 1727.638 & 4090.186 & 6732.894 & 17318.23 & 11461.21 & 15966.5 & 710.299 \\
\hline \multicolumn{8}{|c|}{ After 2008 financial crisis } \\
\hline Mean & -0.001 & -0.001 & -0.001 & -0.001 & -0.002 & -0.001 & -0.002 \\
\hline Median & -0.001 & -0.001 & 0 & -0.001 & -0.003 & -0.001 & -0.006 \\
\hline Max & 0.36 & 0.251 & 0.343 & 0.294 & 0.678 & 0.725 & 0.352 \\
\hline Min & -0.452 & -0.304 & -0.308 & -0.277 & -0.975 & -0.594 & -0.342 \\
\hline SD & 0.03 & 0.029 & 0.031 & 0.031 & 0.081 & 0.055 & 0.063 \\
\hline Skewness & -1.471 & -0.749 & -0.558 & -0.436 & 0.413 & 0.204 & 0.639 \\
\hline kurtosis & 57.683 & 27.893 & 31.426 & 29.762 & 31.941 & 47.374 & 7.382 \\
\hline J-B & 227287.1 & 47135.22 & 61335.43 & 54340.21 & 63531.48 & 149248.2 & 1579.396 \\
\hline
\end{tabular}

Note: SD is standard deviation; J-B is Jarque-Bera statistic.

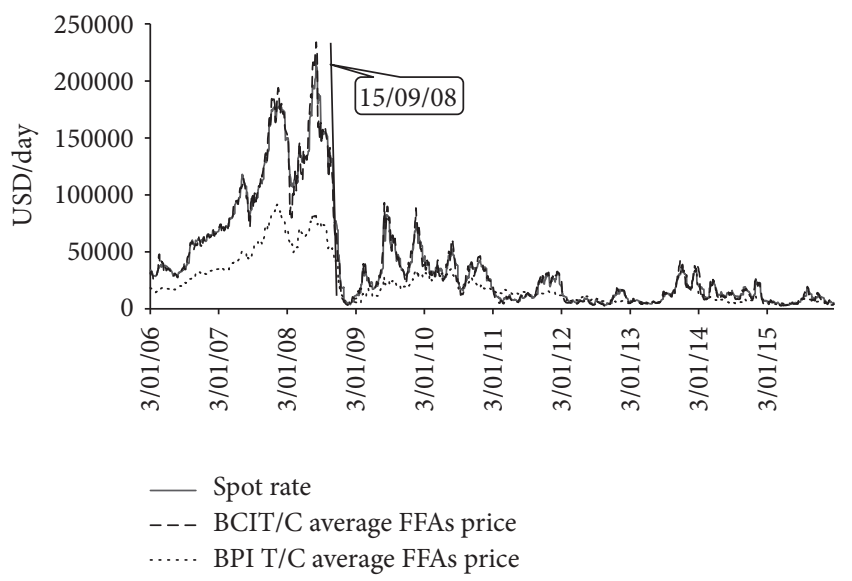

FIgURE 2: FFAs price of $\mathrm{T} / \mathrm{C}$ and spot rate.

a dataset varies from the mean. It is used as an indicator of market volatility and therefore of risk. The bigger value of standard deviation, the greater the risk. After crisis, the values of standard deviations increase for all series studied, which indicates high volatility in FFAs markets.

The second finding is negative skew for most series. Skewness is a measure of symmetry or, more precisely, the lack of symmetry. The values of skewness of four voyage routes Capesize FFAs series are negative skew, which indicates that the tail on the left side of the probability density function is longer or fatter than the right side. The values of skewness of BCIT/C average and BPIT/C average FFAs are positive skew, indicating that the tail on the right side is longer or fatter than the left side. For series of spot rates, the skewness value is negative before the crisis but positive after the crisis.
The last one is that all series are leptokurtic. Kurtosis is a measure of the "tailedness" of the probability distribution of a real-valued random variable. The kurtosis of any univariate normal distribution is 3 . It is common to compare the kurtosis of a distribution to this value. Distributions with kurtosis greater than 3 are said to be leptokurtic, and distributions with kurtosis less than 3 are said to be platykurtic. From the results, all series are leptokurtic. Higher kurtosis means more of the variance is the result of infrequent extreme deviations, as opposed to frequent modestly sized deviations.

Unit root test is a method testing stationary of time series, and the stationary is the basis of modeling VS-MSV. Augmented Dickey-Fuller Test is applied to stationary test in the research. The null hypothesis is that a unit root exists, and alternative hypothesis is without a unit root. The results of unit root test are in Table 3. According to the test results, all series reject the null hypothesis at $1 \%$ level of significant, and it means the series are all stationary, which matches the condition of modeling.

\section{Empirical Analysis}

4.1. Volatility Spillover among Capesize Voyage Routes FFAs. In the paper, Winbugs software is used, with MCMC method, to estimate the parameters of VS-MSV model, and it studies the volatilities spillover effects among Capesize voyage routes FFAs daily return rate, and the number of iterations is 10000 . The results are got when DIC is smallest, shown in Table 4.

According to $t$-statistic, $t(\infty)<t(1819)<t(1000)<$ $t(664)<t(500)$. At a confidence level of $95 \%, t(1000)=$ $1.646, t(500)=1.648$, and $t(\infty)=1.6449$. The absolute value of $t$-statistic for the parameter is not less than 1.648, which means the parameter is significant at $95 \%$ confidence level 
TABLE 3: Examination results of ADF test.

\begin{tabular}{lccccccc}
\hline & C3 & C4 & C5 & C7 & BCIT/C average & BPI T/C average & BCI T/C \\
\hline ADF test before the crisis & -12.845 & -10.598 & -15.217 & -10.185 & -19.752 & -20.513 & -13.568 \\
$1 \%$ level & -2.568 & -2.568 & -2.568 & -2.568 & -2.568 & -2.568 & -2.568 \\
\hline ADF test after the crisis & -23.274 & -23.119 & -23.711 & -15.734 & -37.776 & -37.268 \\
1\% level & -2.566 & -2.566 & -2.566 & -2.566 & -2.566 & -2.566 & -2.566 \\
\hline
\end{tabular}

Note: all concomitant probabilities are equal to zero.

TABLE 4: Volatility spillover among Capesize FFAs.

\begin{tabular}{lccccccccccccccc}
\hline & \multicolumn{4}{c}{ Before the global financial crisis } & \multicolumn{4}{c}{ After the global financial crisis } \\
& Value & MC error & $2.5 \%$ & Median & $97.5 \%$ & $t$ & Value & MC error & $2.5 \%$ & Median & $97.5 \%$ & $t$ \\
\hline$\varphi_{12}$ & 0.692 & 0.025 & 0.302 & 0.729 & 0.978 & 3.162 & -0.011 & 0.007 & -0.113 & 0.000 & 0.103 & -0.185 \\
$\varphi_{13}$ & 0.152 & 0.010 & 0.018 & 0.175 & 0.299 & 1.755 & 0.268 & 0.016 & 0.141 & 0.193 & 0.577 & 1.960 \\
$\varphi_{14}$ & -0.090 & 0.006 & -0.204 & -0.080 & 0.000 & -1.754 & -0.143 & 0.012 & -0.457 & -0.107 & -0.060 & -1.413 \\
$\varphi_{21}$ & -0.037 & 0.011 & -0.256 & -0.028 & 0.112 & -0.391 & 0.573 & 0.012 & 0.444 & 0.540 & 0.814 & 5.362 \\
$\varphi_{23}$ & 0.089 & 0.008 & -0.047 & 0.095 & 0.242 & 1.205 & 0.747 & 0.008 & 0.666 & 0.721 & 0.899 & 11.137 \\
$\varphi_{24}$ & -0.124 & 0.009 & -0.280 & -0.107 & -0.001 & -1.564 & -0.373 & 0.009 & -0.627 & -0.341 & -0.318 & -4.617 \\
$\varphi_{31}$ & 0.221 & 0.029 & -0.068 & 0.119 & 0.788 & 0.883 & 0.463 & 0.013 & 0.346 & 0.427 & 0.775 & 4.159 \\
$\varphi_{32}$ & 0.657 & 0.028 & 0.327 & 0.785 & 0.962 & 2.701 & 0.128 & 0.015 & -0.210 & 0.178 & 0.256 & 0.945 \\
$\varphi_{34}$ & -0.093 & 0.011 & -0.294 & -0.067 & 0.029 & -0.949 & -0.080 & 0.015 & -0.464 & -0.021 & 0.012 & -0.598 \\
$\varphi_{41}$ & 0.137 & 0.062 & -0.473 & -0.129 & 0.967 & 0.253 & 0.394 & 0.047 & -0.377 & 0.646 & 0.704 & 0.946 \\
$\varphi_{42}$ & 0.916 & 0.008 & 0.771 & 0.936 & 0.996 & 13.616 & 0.946 & 0.004 & 0.857 & 0.950 & 0.997 & 26.750 \\
$\varphi_{43}$ & 0.525 & 0.028 & 0.187 & 0.519 & 0.847 & 2.137 & 0.677 & 0.008 & 0.596 & 0.652 & 0.895 & 9.205 \\
\hline
\end{tabular}

Note: MC error is Monte Carlo errors.

before the crisis, and after crisis the absolute value of $t$-statistic should be not less than 1.646 .

From Table 4, the three empirical findings are as follows. The first is that the financial crisis can change relationships of spillover effects. Before the crisis, there are no effects from $\mathrm{C} 3$ to $\mathrm{C} 4, \mathrm{C} 5$, and $\mathrm{C} 7$ and from $\mathrm{C} 5$ and $\mathrm{C} 7$ to $\mathrm{C} 4$, but from $\mathrm{C} 4$ and $\mathrm{C} 7$ to $\mathrm{C} 3$ and $\mathrm{C} 5$ and from $\mathrm{C} 3$ and $\mathrm{C} 7$ after the crisis. The reasons are two. On the one hand, the crisis changes the supply-demand relationships of shipping routes, which could influence the volatility relationships. As we know, the Capesize ship could run on many routes if there are no limits, such as ports draft. After crisis, changes of shipping demands of routes are different, and the transport capacity supplies change accordingly. This would change the volatility relationships between different routes. On the other hand, crisis changes behaviors of participators in FFAs markets and then impact on volatility relationships. After crisis, some investment banks and financing institutions, such as Goldman Sachs and Morgan Stanley, withdrew from FFAs markets.

The second finding is that, before crisis, there are significant spillover effects from $\mathrm{C} 4, \mathrm{C} 5$, and $\mathrm{C} 7$ to $\mathrm{C} 3$, yet there are no effects from $\mathrm{C} 3$ to $\mathrm{C} 4, \mathrm{C} 5$, and $\mathrm{C} 7$. The $\mathrm{C} 3$ route is the longest in all four voyage routes, about 10000 nautical miles, and shipping demand is large. The biggest ships always run on this route due to scale economies effect, for example, Valemax ships, with a capacity ranging from 380,000 to 400,000 tons deadweight. Due to limits, such as port draft, it is hard for these large carriers to run on other routes. So there were no significant spillover effects from C3 to other routes. On the contrary, the ships running on $\mathrm{C} 4, \mathrm{C} 5$, and $\mathrm{C} 7$ could operate on $\mathrm{C} 3$. So volatility of $\mathrm{C} 3$ route would be influenced by other routes.

The last one is that there are bilateral effects between C5 and C3. C3 and C5 are both iron shipping routes, and demand of one route would affect the other. Risk of financial crisis transfers between the two FFAs markets, and then there are bilateral spillover effects.

4.2. Volatility Spillover among Capesize FFAs, Panamax FFAs, and Spot Rate. Table 5 is the results of volatility spillover effects between Capesize FFAs and spot rate when the DIC is smallest. From the results, there is a spillover effect from Capesize spot rate to FFAs before the global financial crisis, and there are bilateral spillover effects after crisis. The first reason is that FFAs is derivative of spot rates, and spot market is foundation of FFAs market. Before crisis, the shipping business was brisk, and many firms traded in FFAs markets. And settlements of FFAs depend on spot rates. So there is spillover volatility from spot rates to FFAs. Besides, FFAs market could diversify away risks in spot market and help manage risks and this indicates risks transmission from spot rate to FFAs. The second reason is the mechanism of transmitting of finance risks. After crisis, many companies withdrew from FFAs markets, speculative bubbles burst, and the financial risks transfer to spot rates, which makes spot rate fall.

Table 6 is the results of volatility spillover effects among volatility spillover among Capesize FFAs, Panamax FFAs, and spot rate when the DIC is smallest. From the results, the 
TABLE 5: Volatility spillover between Capesize FFA and spot rate.

\begin{tabular}{cccccccccccccc}
\hline & \multicolumn{4}{c}{ Before the global financial crisis } & \multicolumn{4}{c}{ After the global financial crisis } \\
& Value & MC error & $2.5 \%$ & Median & $97.5 \%$ & $t$ & Value & MC error & $2.5 \%$ & Median & $97.5 \%$ & $t$ \\
\hline$\varphi_{12}$ & 0.851 & 0.007 & 0.687 & 0.847 & 0.974 & 11.130 & 0.245 & 0.003 & 0.192 & 0.245 & 0.308 & 9.911 \\
$\varphi_{21}$ & 0.013 & 0.004 & -0.051 & 0.024 & 0.070 & 0.338 & 0.585 & 0.008 & 0.422 & 0.606 & 0.655 & 8.790 \\
\hline
\end{tabular}

TABle 6: Volatility spillover among Capesize FFAs, Panamax FFAs, and BCI.

\begin{tabular}{lcccccccccccccc}
\hline & \multicolumn{4}{c}{ Before the global financial crisis } & \multicolumn{4}{c}{ After the global financial crisis } \\
& Value & MC error & $2.5 \%$ & Median & $97.5 \%$ & $t$ & Value & MC error & $2.5 \%$ & Median & $97.5 \%$ & $t$ \\
\hline$\varphi_{12}$ & 0.921 & 0.005 & 0.811 & 0.927 & 0.991 & 19.015 & -0.159 & 0.005 & -0.221 & -0.171 & -0.047 & -3.650 \\
$\varphi_{13}$ & 0.889 & 0.009 & 0.688 & 0.916 & 0.992 & 10.461 & 0.287 & 0.011 & 0.114 & 0.281 & 0.559 & 2.807 \\
$\varphi_{21}$ & 0.106 & 0.004 & -0.009 & 0.113 & 0.159 & 2.698 & 0.888 & 0.009 & 0.645 & 0.911 & 0.990 & 10.062 \\
$\varphi_{23}$ & 0.724 & 0.015 & 0.459 & 0.751 & 0.923 & 5.368 & 0.754 & 0.011 & 0.479 & 0.758 & 0.956 & 7.378 \\
$\varphi_{31}$ & -0.0180 & 0.005 & -0.241 & -0.192 & -0.092 & -0.439 & 0.730 & 0.021 & 0.176 & 0.779 & 0.971 & 3.796 \\
$\varphi_{32}$ & 0.0366 & 0.009 & 0.147 & 0.380 & 0.508 & 0.433 & 0.165 & 0.007 & 0.031 & 0.186 & 0.239 & 2.752 \\
\hline
\end{tabular}

similar conclusions are with Table 5. Before the crisis, there is no effect from FFAs to spot rate, and after the crisis, there are bilateral effects between FFAs and spot rate. Further, the effects between Panamax and Capesize FFAs are mutually, which is due to the substitutability between Capesize and Panamax in practice.

Above all, there are some suggestions for firms trading in FFAs markets. Firstly, it is important to focus on spillover effects between different voyage routes. Price volatility of one route FFAs is influenced not only by its own early stage but also by volatility coming from other routes, due to spillover effects, which would strengthen the volatility. So firms should consider this before sign a FFAs contract. Taking C3 route as an example, if one company would buy a FFAs contract settlement one month later, some factors should be considered for analyzing price volatility, such as history volatility of C3 route and spillovers from C5. Secondly, according to spillover from spot rate to FFAs, the changes of spot markets would affect FFAs markets. So it is necessary to pay attention to factors influencing spot rates, such as supply and demand. Thirdly, there are bilateral relationships between Panamax time-charter FFAs and Capesize time-charter FFAs, so it is important to focus on some factors affecting Panamax shipping market when trading in Capesize FFAs markets.

\section{Conclusion}

The paper studies the volatility spillover effects in Capesize forward freight agreement market using VS-MSV model, and the results show that the effects are different in different routes and markets. The effects exist between certain Capesize routes, and the effects are from spot to FFAs before the global financial crisis, yet bilateral after the crisis.

Some conclusions are as follows. (1) Spillover effects of Capesize FFAs markets are influenced by financial crisis, which changes supply-demand relationships in shipping market and behaviors of participators in FFAs markets. (2) There are significant spillover effects from $\mathrm{C} 4, \mathrm{C} 5$, and $\mathrm{C} 7$ to $\mathrm{C} 3$, yet there are no effects from $\mathrm{C} 3$ to $\mathrm{C} 4, \mathrm{C} 5$, and $\mathrm{C} 7$; there is effect from $\mathrm{C} 5$ to $\mathrm{C} 3$ and from $\mathrm{C} 3$ to $\mathrm{C} 4$ and $\mathrm{C} 5$ after crisis. (3) There is a spillover effect from Capesize spot rate to FFA before the global financial crisis, and there are bilateral spillover effects after crisis. (4) Bilateral effects exist between FFAs and spot rate.

\section{Competing Interests}

The authors declare that they have no competing interests.

\section{Acknowledgments}

This work was supported by project of National Nature Science Foundation of China (71473023), Scientific Research General Project of Liaoning Provincial Education Department (L2015058), and the Fundamental Research Funds for the Central Universities (20110116207).

\section{References}

[1] M. G. Kavussanos, I. D. Visvikis, and D. N. Dimitrakopoulos, "Economic spillovers between related derivatives markets: the case of commodity and freight markets," Transportation Research Part E: Logistics and Transportation Review, vol. 68, pp. 79102, 2014.

[2] Z. Xiong and L. Han, "Volatility spillover effect between financial markets: evidence since the reform of the RMB exchange rate mechanism," Financial Innovation, vol. 1, no. 1, pp. 1-9, 2015.

[3] M. G. Kavussanos and N. K. Nomikos, "Price discovery, causality and forecasting in the freight futures market," Review of Derivatives Research, vol. 6, no. 3, pp. 203-230, 2003.

[4] M. G. Kavussanos and I. D. Visvikis, "Market interactions in returns and volatilities between spot and forward shipping freight markets," Journal of Banking \& Finance, vol. 28, no. 8, pp. 2015-2049, 2004.

[5] G. Peter, Forecasting Shipping Freight Rates, Working Paper Series, Johannes Kepler University Linz, 2010. 
[6] G. Peter, Is the Forward Freight Market Efficient? A Study Investigating the Unbiasedness Hypothesis and Causality in the Shipping Market, Working Paper Series, Johannes Kepler University Linz, 2010.

[7] R. Batchelor, A. Alizadeh, and I. Visvikis, "Forecasting spot and forward prices in the international freight market," International Journal of Forecasting, vol. 23, no. 1, pp. 101-114, 2007.

[8] X.-X. Gong, J. Lv, and Y. Wang, "Relationship between forward freight and spot freight in shipping market," Journal of Dalian Maritime University, vol. 36, no. 1, pp. 55-64, 2010.

[9] S.-K. Chung and J.-H. Weon, "Long memory and asymmetric time varying spillover effects in dry bulk freight markets," Maritime Economics \& Logistics, vol. 15, no. 4, pp. 494-522, 2013.

[10] K. X. Li, G. Qi, W. Shi et al., "Spillover effects and dynamic correlations between spot and forward tanker freight markets," Maritime Policy \& Management, vol. 41, no. 7, pp. 683-696, 2014.

[11] V. Sogiakas and G. Karathanassis, "Informational efficiency and spurious spillover effects between spot and derivatives markets," Global Finance Journal, vol. 27, pp. 46-72, 2015.

[12] G. Alexandridis, S. Sahoo, and I. Visvikis, Economic Information Transmissions between Shipping Markets: New Evidence from Freight Derivatives Markets, 2016.

[13] W. Shi, K. X. Li, Z. Yang, and G. Wang, "Time-varying copula models in the shipping derivatives market," Empirical Economics, 2016.

[14] A. H. Alizadeh, "Trading volume and volatility in the shipping forward freight market," Transportation Research Part E: Logistics and Transportation Review, vol. 49, no. 1, pp. 250-265, 2013.

[15] M. T. Chou, "Research on the relationship between forward freight agreements and the fuel oil index," African Journal of Business Management, vol. 5, no. 20, pp. 8033-8040, 2011.

[16] M. T. Chou, Y. L. Yang, and S. C. Chang, "A study of the dynamic relationship between crude oil price and the steel price index," Review of Economics \& Finance, vol. 2, pp. 30-42, 2012.

[17] M. G. Kavussanos, I. D. Visvikis, and R. A. Batchelor, "Over-thecounter forward contracts and spot price volatility in shipping," Transportation Research Part E: Logistics and Transportation Review, vol. 40, no. 4, pp. 273-296, 2004.

[18] J. Lu, P. B. Marlow, and H. Wang, "An analysis of freight rate volatility in dry bulk shipping markets," Maritime Policy \& Management, vol. 35, pp. 237-251, 2008.

[19] A. H. Alizadeh and N. K. Nomikos, "Dynamics of the term structure and volatility of shipping freight rates," Journal of Transport Economics and Policy, vol. 45, no. 1, pp. 105-128, 2011.

[20] A. H. Alizadeh, C.-Y. Huang, and S. van Dellen, "A regime switching approach for hedging tanker shipping freight rates," Energy Economics, vol. 49, pp. 44-59, 2015.

[21] D. A. Tsouknidis, "Dynamic volatility spillovers across shipping freight markets," Transportation Research Part E: Logistics and Transportation Review, vol. 91, pp. 90-111, 2016.

[22] A. C. Harvey and N. Shephard, "Estimation of an asymmetric stochastic volatility model for asset returns," Journal of Business \& Economic Statistics, vol. 14, no. 4, pp. 429-434, 1996.

[23] J. Yu, "On leverage in a stochastic volatility model," Journal of Econometrics, vol. 127, no. 2, pp. 165-178, 2005.

[24] O. E. Barndorff-Nielsen and R. Stelzer, "The multivariate supOU stochastic volatility model," Mathematical Finance, vol. 23, no. 2, pp. 275-296, 2013.

[25] P. Hagan, A. Lesniewski, and D. Woodward, "Probability distribution in the SABR model of stochastic volatility", in Large
Deviations and Asymptotic Methods in Finance, Springer International Publishing, 2015.

[26] Z. Xu and S. Zhang, "The comparative research on volatility prediction ability of adjusted realized volatility, GARCH model and SV model," Systems Engineering, vol. 8, pp. 6-63, 2004.

[27] Y. Wei, "Forecasting volatility of fuel oil futures in China: GARCH-type, SV or realized volatility models?" Physica A: Statistical Mechanics and Its Applications, vol. 391, no. 22, pp. 5546-5556, 2012.

[28] A. Harvey, E. Ruiz, and N. Shephard, "Multivariate stochastic variance models," Review of Economic Studies, vol. 61, no. 2, pp. 247-264, 1994.

[29] M. K. So, W. K. Li, and K. Lam, "Multivariate modelling of the autoregressive random variance process," Journal of Time Series Analysis, vol. 18, no. 4, pp. 429-446, 1997.

[30] R. F. Zhang and S. Y. Zhang, "Volatility spillover analysis and empirical study on the financial market based on VS-MSV model," Systems Engineering, vol. 25, no. 8, pp. 1-6, 2007.

[31] D. J. Spiegelhalter, N. Best, B. P. Carlin et al., "Bayesian deviance, the effective number of parameters, and the comparison of arbitrarily complex models," in Research Report, Division of Biostatistics, pp. 1-31, University of Minnesota, 1998.

[32] S. Kim, N. Shephard, and S. Chib, "Stochastic volatility: likelihood inference and comparison with ARCH models," The Review of Economic Studies, vol. 65, no. 3, pp. 361-393, 1998.

[33] L. F. Meng, S. Y. Zhang, and X. He, "Bayesian analysis of stochastic volatility model with leverage effect and its application," Systems Engineering, vol. 22, no. 3, pp. 47-51, 2004.

[34] H. Liu and T. Tu, "An investigation on volatility and the interrelationship between the us equity market and macroeconomic variables-an application of the VEC GJR DCC-GARCH-M model," Taipei Economic Inquiry, vol. 48, no. 1, p. 139, 2012.

[35] X. Wang and M. Sun, "Influence and enlightenment of international financial crisis on development of country economy," Theory Journal, no. 7, pp. 48-51, 2009. 

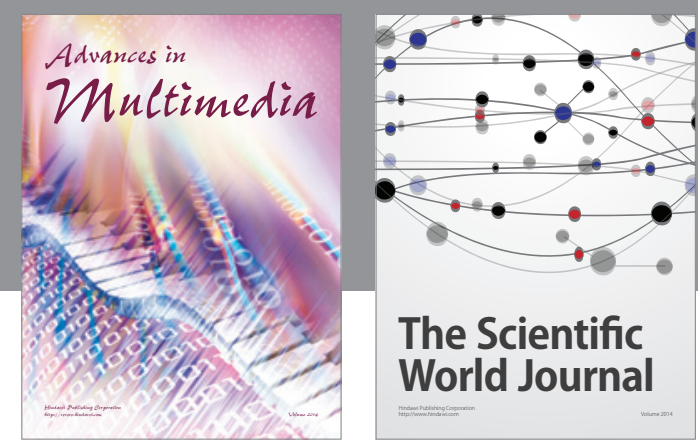

The Scientific World Journal
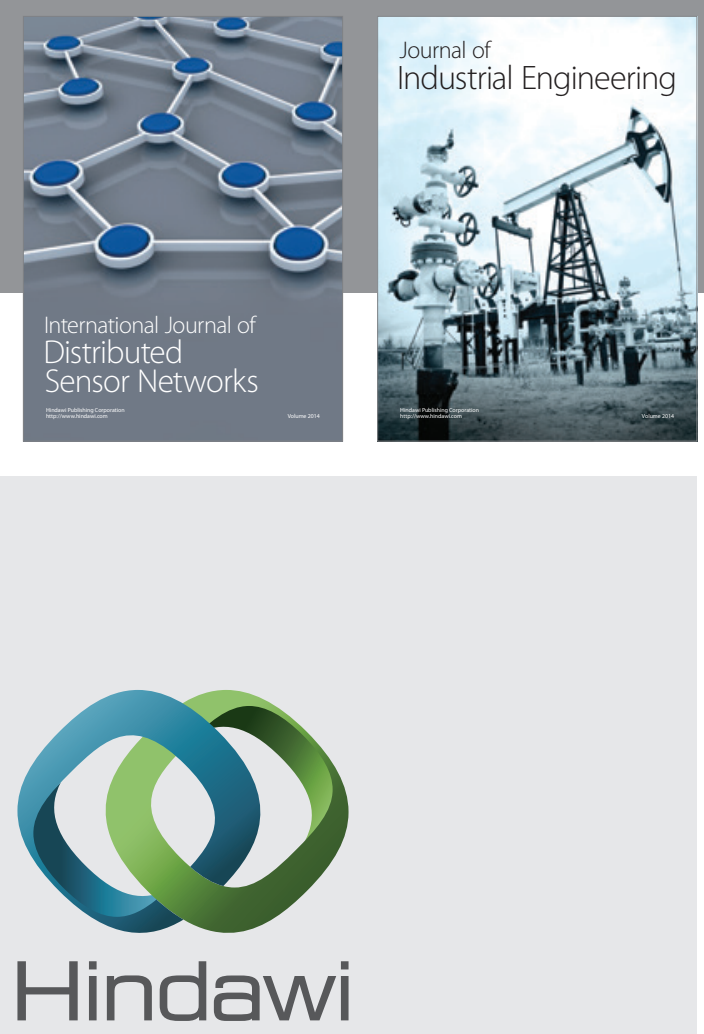

Submit your manuscripts at

http://www.hindawi.com

\section{Computer Networks} and Communications
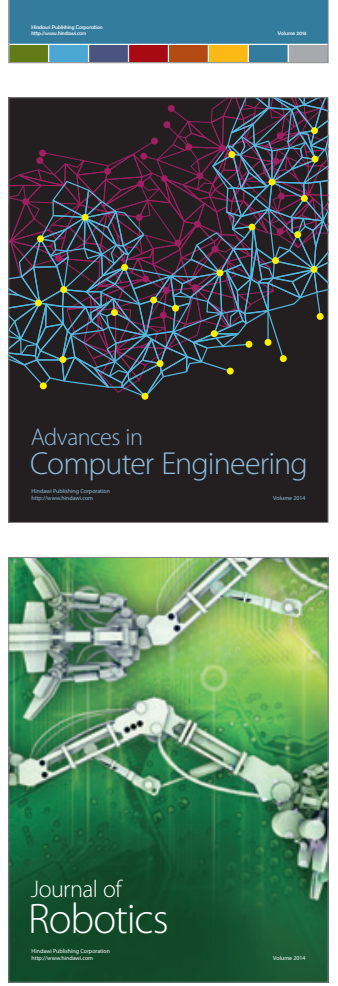
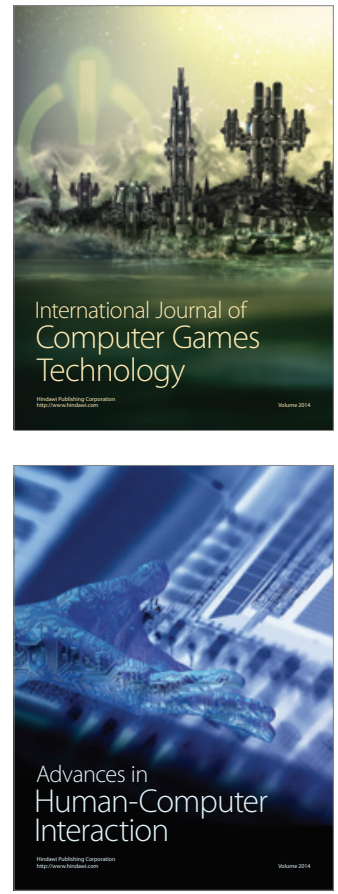
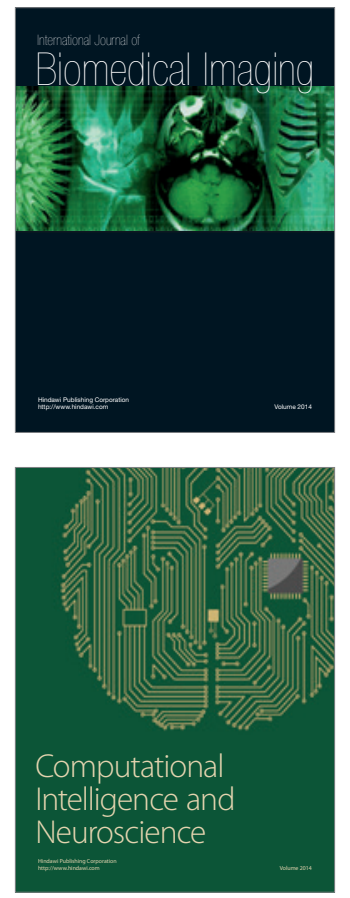
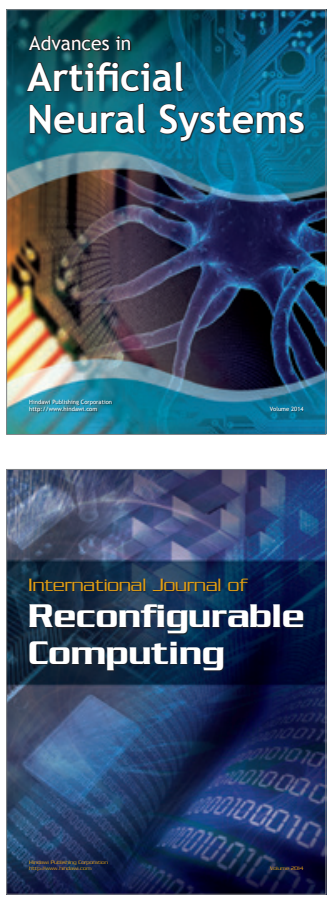
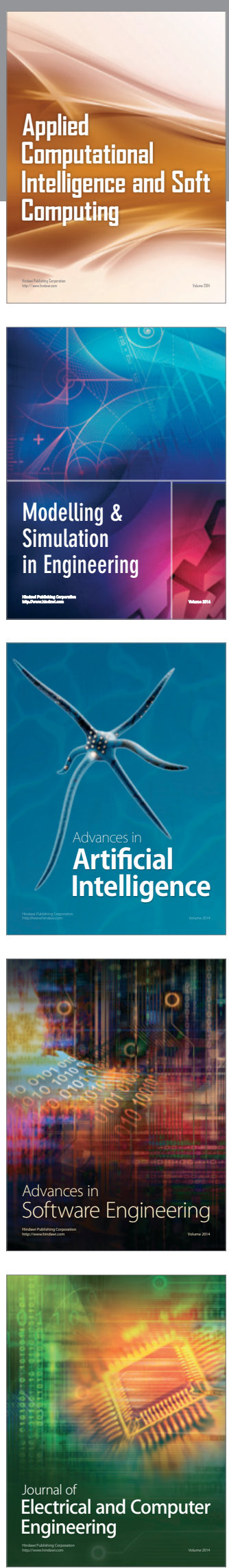